\title{
The Polish version of Skindex-29: psychometric properties of an instrument to measure quality of life in dermatology
}

\author{
Konrad Janowski ${ }^{1}$, Stanisława Steuden ${ }^{2}$, Bernarda Bereza ${ }^{2}$ \\ ${ }^{1}$ Department of Psychology, University of Finance and Management, Warsaw, Poland \\ Head of Department: Prof. Stanisław Mika PhD \\ 2Department of Clinical Psychology, John Paul II University of Lublin, Lublin, Poland \\ Head of Department: Prof. Stanisława Steuden PhD
}

Postep Derm Alergol 2014; XXXI, 1: 12-20

DOI: $10.5114 / p d i a .2014 .40654$

\begin{abstract}
Introduction: Skin conditions have a negative impact on quality of life and it is necessary to quantify this impact. Skindex-29 is a self-report questionnaire developed to measure dermatology-specific quality of life.

Aim: The objective of this study is to adapt this questionnaire to Polish conditions. The adaptation procedure involved the works on the linguistic content of the items and testing psychometric properties of the Polish version of Skindex-29, including item characteristics, factorial structure, aspects of reliability and validity.

Material and methods: Two-hundred and ninety patients ( $63.4 \%$ women and $35.2 \%$ men) suffering from a range of skin conditions were recruited from several dermatological out-patient and in-patient clinics in Poland. Quality of life was measured using Skindex-29 and appropriate clinical data were collected.

Results: The global score of Skindex-29 showed the normal distribution. Cronbach's $\alpha$ reliability coefficients were found to be high to very high for all Skindex-29 indexes. Factor analysis yielded four factors, in contrast to the original version of the questionnaire, for which a three-factor solution had been reported. Skindex-29 validity was demonstrated by showing the differences in the quality of life scores across different diagnostic categories, and between in-patients and out-patients. Skindex-29 global scores were found to be significantly predicted by the localization of the skin lesions on legs, anogenital areas and palms.

Conclusions: The findings of this study support reliability and validity of the Polish version of Skindex-29, but they also raise questions to its three-factor structure.
\end{abstract}

Key words: psychodermatology, psychometric assessment, quality of life.

\section{Introduction}

Most dermatological conditions can have a considerable impact on quality of life in afflicted individuals [1-4]. Therefore, the need for evaluation of various quality of life domains in dermatological patients has received a growing interest and recognition for the last two decades $[5,6]$. To address this need, numerous instruments have been developed to measure both disease-specific [7-13] and dermatology-specific [14-17] quality of life.

Skindex-29 is one of such instruments [18]. It was developed and designed to measure dermatology-specific quality of life $[19,20]$. The first version of the test was developed in 1996 in the U.S. by Chren et al. [19]. The intention of the authors was to develop a test that would make it possible to: (1) capture the differences in the impact of skin disease on quality of life in patients with different dermatological conditions, and (2) assess the changes in quality of life accompanying the changes occurring in the clinical status. The method consisted of 61 items comprising eight subscales, corresponding to different dimensions of quality of life as conceptualized by the authors. The item contents were based on extensive literature review and direct interviews with dermatological patients, dermatologists and dermatological nurses. The questionnaire was found to have high reliability, and convergent and discriminative validity [20].

It was noted however, that the length of the questionnaire (the time needed to complete the test was about

Address for correspondence: Dr Konrad Janowski, Department of Psychology, University of Finance and Management, 55 Pawia St, 01-030 Warsaw, Poland, phone: +48 506742 462, e-mail: janowski@kul.pl, janowski@vizja.pl Received: 31.10.2012, accepted: 2.04.2013. 
$15 \mathrm{~min}$ ) did not encourage its implementation in routine clinical situations. Some items were also found to show low discriminative ability, and some subscales showed poor sensitivity to changes in the clinical status of patients. In consequence, the authors decided to revise Skindex [18].

In 1997, modifications were introduced into the instrument, including elimination of the items which did not meet the psychometric requirements sufficiently. Some of the remaining items were reformulated so as to increase their discriminative ability and sensitivity to even small differences in the impact of the skin disease on quality of life. To strengthen the individual subscales, five new items were added. Factor analyses showed that three principal factors could be extracted, and these factors were taken as the basis for three subscales, replacing the former eight subscales [18].

In this way, a revised version of Skindex was obtained. It consisted of 29 statements expressing the effects that skin diseases can have on quality of life. Items are arranged in three subscales: (1) Physical symptoms - 7 items, (2) Emotions - 10 items, (3) Functioning (daily activities, fulfilling social roles and interpersonal interactions) -12 items.

In a review article on questionnaires measuring quality of life in psoriasis, Skindex-29 was distinguished out of other similar instruments and highly appraised for its high conceptual and psychometric properties [21]. Reliability, as measured by Cronbach's $\alpha$ coefficient of internal consistency, was 0.87 for the Physical symptoms subscale, 0.94 for the Emotions subscale and 0.96 for the Functioning subscale. Pearson's $r$ correlation coefficients - estimating repeatability between two measurements made at an interval of $72 \mathrm{~h}$ (the test-retest reliability) - were 0.91, 0.88 and 0.92 for Physical symptoms, Emotions and Functioning, respectively. All the subscales demonstrated sensitivity to changes in the patient's clinical status. The relevance of the item contents was evaluated by comparing the semantic content of Skindex-29 items with written statements of 591 patients, who were asked to list the aspects of skin diseases that are the most burdensome for them. The tests confirmed good agreement between the content of the questionnaire items and the statements freely generated by patients [18]. The utility of Skindex-29 has been confirmed in studies on quality of life in patients suffering from various skin conditions [3, 22-24].

Adaptations of Skindex-29 have already been made into several languages, including Italian [25], Spanish [26], Tunisian [27] and French [28]. The authors also developed an abbreviated version of the questionnaire, Skindex-16 [29], which has already been translated into Japanese [30].

\section{Aim}

The objective of this paper is to present the findings of research undertaken to adapt Skindex-29 to Polish conditions, in particular to present psychometric properties of the Polish version of this questionnaire.

\section{Material and methods \\ The adaptation procedure}

The adaptation procedure consisted of two stages. The first stage involved the works on the linguistic content of the items aimed at ensuring both faithfulness to the original and cultural adequacy to Polish conditions. The second stage consisted in the study aimed at testing psychometric properties of the Polish version of Skindex-29: properties of the items, factorial structure, aspects of reliability and validity.

The goal of the translation procedure was to maintain the faithfulness of the translated items to their English original and, at the same time, to ensure cultural adequacy of the content of the items to Polish conditions. First, the items were translated into Polish independently by 10 students of the English Philology. The obtained translations were reviewed by a committee of 14 participants of the Master's seminar in clinical psychology and the best translation was chosen for each item according to three criteria: linguistic correctness, faithfulness to the original and comprehensibility. Then, the items were back-translated by a bilingual person, with American English as his first language. The back-translations were sent to the American author of the questionnaire for conceptual review. The items evaluated as conceptually equivalent to the American ones were included into the Polish version. The items evaluated as non-equivalent underwent the same procedure of translations and back-translations with the exception that the modifications suggested by the American author were suggested to the translators. The procedure was repeated until all items fulfilled the assumed linguistic criteria of acceptability.

\section{Scoring}

The Polish version of the questionnaire adopted the same scoring method as the original American version. For each item, the respondents endorse the frequency of a given disease-related experience (never, rarely, sometimes, often, all the time), and the responses are scored on a 5-point scale. The total score is a sum of scores for all items providing an index of quality of life, it can range from 29 (high quality of life - no negative impact of the disease) to 145 (low quality of life - the greatest negative impact of the disease). The scores can also be calculated for each subscale. The time needed to complete the test is approximately $5 \mathrm{~min}$. The period that patients take into account when assessing the impact of the disease on different spheres of their life is the same as in the original version -4 weeks.

\section{Participants}

To test psychometric properties of the Polish version of Skindex-29, 290 dermatological patients were recruit- 
Table 1. Frequency of dermatological diagnoses in the sample

\begin{tabular}{|c|c|c|c|c|c|}
\hline Condition & $N$ & $\%$ & Condition & $N$ & $\%$ \\
\hline Skin allergy & 19 & 6.6 & Shingles & 1 & 0.3 \\
\hline Atopic dermatitis & 2 & 0.7 & Keratoderma & 1 & 0.3 \\
\hline Vitiligo & 2 & 0.7 & Striae & 1 & 0.3 \\
\hline Warts & 19 & 6.6 & Erythema & 5 & 1.7 \\
\hline Dermatitis herpetiformis & 1 & 0.3 & Systemic sclerosis & 10 & 3.4 \\
\hline Furuncle & 1 & 0.3 & Pruritus & 1 & 0.3 \\
\hline Mycosis & 10 & 3.4 & Lipoma & 1 & 0.3 \\
\hline Condyloma & 1 & 0.3 & Systemic lupus erythematosus & 3 & 1.0 \\
\hline Contact dermatitis & 1 & 0.3 & Acne vulgaris & 59 & 20.3 \\
\hline Lichen planus & 5 & 1.7 & Rosacea & 3 & 1.0 \\
\hline Pityriasis amiantacea & 1 & 0.3 & Eczema & 5 & 1.7 \\
\hline Psoriasis & 52 & 17.9 & Bacterial skin infection & 4 & 1.4 \\
\hline Androgenic alopecia & 2 & 0.7 & Dermatitis & 2 & 0.7 \\
\hline Alopecia areata & 1 & 0.3 & Thrombophlebitis superficialis & 2 & 0.7 \\
\hline Leg ulcers & 9 & 3.1 & Mycosis fungoides & 1 & 0.3 \\
\hline Pemphigus & 3 & 1.0 & Multiple dermatologic diagnoses & 5 & 1.7 \\
\hline Nevi & 2 & 0.7 & Missing data & 52 & 17.9 \\
\hline Urticaria & 2 & 0.7 & Total & 290 & 100.0 \\
\hline Burn & 1 & 0.3 & & & \\
\hline
\end{tabular}

ed from several dermatological out-patient and in-patient clinics in Poland. All participants were treated or sought treatment for a dermatological condition. One-hundred and eighty-four (63.4\%) participants were women and 102 (35.2\%) were men. Four participants (1.4\%) did not provide information on their gender. The age of the

Table 2. Frequency of patients reporting the occurrence of dermatological lesions on particular body parts

\begin{tabular}{lcc}
\hline Affected body parts & $\boldsymbol{N}$ & $\%$ \\
\hline Face & 123 & 50.4 \\
\hline Neck & 49 & 20.1 \\
\hline Head & 55 & 22.5 \\
\hline Palms & 69 & 28.3 \\
\hline Arms & 78 & 32.0 \\
\hline Trunk & 79 & 32.4 \\
\hline Legs & 112 & 45.9 \\
\hline Anogenital areas & 28 & 11.5 \\
\hline
\end{tabular}

participants ranged from 16 to 82 , with the mean age of $M=36.14$ (SD = 16.64). $12.8 \%$ of the patients were graduates of the elementary school, $11.4 \%$ - vocational school, 56.9\% - high school and 14.8\% - were university graduates. $4.1 \%$ did not fill in the information about their educational level. All subjects were informed about the nature of the study and they were enrolled into the study after receiving their informed consent. All patients were asked to fill in Skindex-29 and a brief questionnaire collecting basic sociodemographic and clinical data.

\section{Results}

\section{Clinical characteristics of the sample}

The participants presented with a wide range of dermatological conditions. $17.9 \%$ of the participants failed to provide information about their current dermatological condition. Table 1 presents the frequency of dermatological diagnoses in the sample. $64.1 \%$ of the patients were treated at an out-patient clinic and $35.9 \%$ of the patients were hospitalized due to their dermatologic condition at the time of the study. The duration of the disease ranged from 0.1 year to 65 years, the mean duration was $M=8.37(S D=10.69)$ years. Table 2 presents the number 
Table 3. Descriptive statistics and normality tests for the Skindex-29 indexes

\begin{tabular}{|c|c|c|c|c|c|c|c|c|}
\hline \multirow[t]{2}{*}{ Skindex-29 indexes } & \multirow[t]{2}{*}{ Minimum } & \multirow[t]{2}{*}{ Maximum } & \multirow[t]{2}{*}{ Mean } & \multirow[t]{2}{*}{$\begin{array}{l}\text { Standard } \\
\text { deviation }\end{array}$} & \multirow[t]{2}{*}{ Skewness } & \multirow[t]{2}{*}{ Kurtosis } & \multicolumn{2}{|c|}{$\begin{array}{c}\text { Kolmogorov-Smirnov } \\
\text { normality test }\end{array}$} \\
\hline & & & & & & & $z$ & $p$ \\
\hline Physical symptoms & 7 & 32 & 17.97 & 6.13 & 0.12 & -0.89 & 1.41 & 0.038 \\
\hline Functioning & 12 & 60 & 28.25 & 12.62 & 0.53 & -0.82 & 2.16 & $<0.001$ \\
\hline Emotions & 10 & 50 & 28.25 & 10.08 & 0.08 & -0.80 & 0.97 & 0.301 \\
\hline Total score & 29 & 142 & 74.47 & 26.56 & 0.34 & -0.78 & 1.08 & 0.193 \\
\hline
\end{tabular}

Table 4. Psychometric properties of Skindex-29 items

\begin{tabular}{|c|c|c|c|}
\hline $\begin{array}{l}\text { Item } \\
\text { number }\end{array}$ & Mean & $\begin{array}{l}\text { Standard } \\
\text { deviation }\end{array}$ & $\begin{array}{l}\text { Corrected item-total } \\
\text { correlation }\end{array}$ \\
\hline 1 & 2.31 & 1.16 & 0.57 \\
\hline 2 & 2.28 & 1.36 & 0.65 \\
\hline 3 & 2.87 & 1.41 & 0.66 \\
\hline 4 & 2.64 & 1.53 & 0.77 \\
\hline 5 & 2.89 & 1.39 & 0.74 \\
\hline 6 & 3.06 & 1.23 & 0.79 \\
\hline 7 & 2.58 & 1.28 & 0.61 \\
\hline 8 & 2.42 & 1.37 & 0.74 \\
\hline 9 & 2.60 & 1.40 & 0.48 \\
\hline 10 & 2.83 & 1.28 & 0.55 \\
\hline 11 & 2.20 & 1.39 & 0.71 \\
\hline 12 & 2.93 & 1.31 & 0.72 \\
\hline 13 & 3.34 & 1.14 & 0.67 \\
\hline 14 & 2.31 & 1.35 & 0.71 \\
\hline 15 & 2.67 & 1.36 & 0.63 \\
\hline 16 & 2.09 & 1.29 & 0.40 \\
\hline 17 & 2.07 & 1.28 & 0.68 \\
\hline 18 & 3.02 & 1.20 & 0.68 \\
\hline 19 & 2.41 & 1.33 & 0.74 \\
\hline 20 & 2.91 & 1.29 & 0.74 \\
\hline 21 & 2.48 & 1.44 & 0.69 \\
\hline 22 & 2.80 & 1.38 & 0.76 \\
\hline 23 & 3.39 & 1.34 & 0.47 \\
\hline 24 & 2.20 & 1.34 & 0.76 \\
\hline 25 & 2.31 & 1.42 & 0.75 \\
\hline 26 & 1.75 & 1.07 & 0.56 \\
\hline 27 & 2.75 & 1.25 & 0.72 \\
\hline 28 & 1.87 & 1.29 & 0.62 \\
\hline 29 & 2.47 & 1.39 & 0.75 \\
\hline
\end{tabular}

of participants reporting the presence of dermatological lesions on particular body areas.

\section{Descriptive statistics obtained for Skindex-29 scores in the whole sample}

Table 3 contains descriptive statistics for the Skindex-29 total score and subscales. The distributions of all the indexes are slightly positively skewed and platykurtic. The distributions were found to be significantly different from the normal distribution for Physical symptoms and Functioning, however the empirical distributions did not differ from the normal distribution for Emotions and the Total score.

\section{Psychometric properties of Skindex-29 items}

The psychometric properties of individual Skindex-29 items are satisfactory or high. The corrected item-total correlations ranged from 0.40 to 0.79 . The mean item values are distributed closely to 2.5 which is the central value of the response scale (Table 4).

\section{Reliability}

Reliability of the Polish version of Skindex-29, as measured by internal consistency (Cronbach's $\alpha$ ), was high for Physical symptoms (>0.80) and very high for the remaining subscales and the total score (>0.90) (Table 5). These values are indicative of very high reliability of the questionnaire.

\section{Factor analysis}

Factor analysis yielded the four-factor solution, with the factors extracted according to the criterion of eigenvalues higher than 1.0 (Figure 1). This solution is different

Table 5. Reliability of Skindex-29 indexes

\begin{tabular}{lcc}
\hline Skindex-29 indexes & No. of items & Cronbach's $\alpha$ \\
\hline Physical symptoms & 7 & 0.84 \\
\hline Functioning & 12 & 0.94 \\
\hline Emotions & 10 & 0.92 \\
\hline Total score & 29 & 0.96 \\
\hline
\end{tabular}




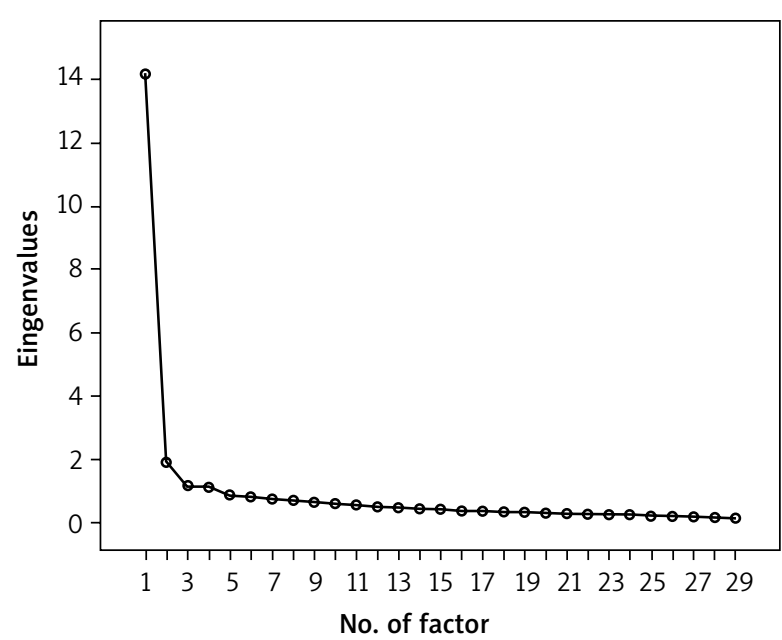

Figure 1. Screen-plot for the factors extracted in factor analysis with the criterion of eigenvalues higher than 1.0

from the three-factor solution reported for the original version, which was the basis for subscales development. One extra factor (factor 2) was combined of 9 items that originally belonged to the Physical symptoms and Functioning subscales. The remaining items (except for item 25) loaded on the factors corresponding to their original subscales (Table 6). Altogether, the four extracted factors accounted for more than $63 \%$ of variance in the test (Table 7).

\section{Skindex-29 scores in major diagnostic category groups}

Out of the total sample, four subgroups of patients with the most frequent diagnoses were identified: patients with psoriasis (17.9\% of the total sample), acne vulgaris (20.3\%), warts (6.6\%) and skin allergies (6.6\%). Patients with other conditions were excluded from this analysis due to low frequency of their conditions, which would disabled statistical analyses. The four subgroups were compared on the scores obtained on Skindex-29. The means, standard deviations and significance of the differences between the groups are presented in Table 8 and Figure 2.

ANOVA F-test showed statistically significant differences between the subgroups for all the indexes of Skindex-29. In each case, the highest scores (lowest quality of life) were found for patients with psoriasis, and the lowest for patients with warts. In the scores of Physical symptoms, post-hoc test showed, however, that patients with acne vulgaris did not differ significantly from patients with skin allergies, whereas the differences between all other subgroups were significant $(p<0.001)$. In the Functioning subscale, psoriasis patients scored significantly higher than the remaining subgroups ( $p<0.001)$, no significant differences were observed between the remaining subgroups. In the Emotions subscale, patients with skin allergy did not differ significantly from those with acne vulgaris and warts, the remaining subgroups showed statistically significant differences. In the total score, again, patients with acne were not significantly different from those with skin allergies, however, other subgroups were all significantly different.

\section{Skindex-29 scores in in-patients vs. out-patients}

The differences on the Skindex-29 scores were also analyzed between in-patients and out-patients (Table 9). The in-patients scored significantly higher on all the indexes of quality of life than the out-patients, which points to markedly compromised quality of life domains in dermatologic in-patients as compared to out-patients (Table 9 and Figure 3).

\section{Skindex-29 scores and the localization of skin lesions}

A series of stepwise regression analyses was carried out with the indexes of Skindex-29 introduced as dependent variables, and localization of skin lesions on particular body areas ( 8 body areas - cf. Table 2 ) entered as independent variables. Table 10 presents the values of standardized regression coefficients and parameters of the models obtained for each quality of life domain and for the global quality of life score.

The presence of skin lesions on legs and anogenital areas was found to be a stable statistically significant predictor of lower quality of life across all three quality of life domains and the global quality of life index. Additionally, the presence of lesions on palms was a specific predictor of lower global quality of life and lower functioning, whereas the presence of lesions on the face was a specific predictor of more severe physical symptoms. The presence of lesions on legs was the strongest predictor for all quality of life indexes ( $\beta$ ranging from 0.28 to 0.38 ). The contribution of the location of the lesions to the variance in quality of life was the highest for Functioning (approximately 25\% of explained variance) and the lowest for Emotions (approximately 12\% of explained variance).

\section{Discussion}

Dermatological diseases have a significant impact on quality of life. Therefore, monitoring quality of life of dermatological patients is certainly an important part of clinical treatment. This gives an opportunity to improve the effectiveness of possible treatments [31]. Essential in this process is the selection of appropriate diagnostic methods, especially those already standardized and recognized by medical and psychological professionals from many countries [25, 26, 30, 32]. Such tools are commonly translated and adapted for wider use in different countries and cultures, however, in such context, their 
Table 6. Factor loadings obtained in factor analysis for Skindex-29

\begin{tabular}{|c|c|c|c|c|c|}
\hline \multirow[t]{2}{*}{ Item no. } & \multicolumn{5}{|c|}{ Factor number } \\
\hline & Original scale & 1 (Functioning) & 2 & 3 (Emotions) & 4 (Physical symptoms) \\
\hline 17 & $\mathrm{~F}$ & 0.76 & 0.20 & 0.17 & 0.24 \\
\hline 19 & $\mathrm{~F}$ & 0.74 & 0.22 & 0.35 & 0.11 \\
\hline 28 & $\mathrm{~F}$ & 0.71 & 0.22 & 0.07 & 0.27 \\
\hline 24 & $\mathrm{~F}$ & 0.69 & 0.29 & 0.41 & 0.04 \\
\hline 14 & $\mathrm{~F}$ & 0.63 & 0.29 & 0.29 & 0.20 \\
\hline 11 & $\mathrm{~F}$ & 0.61 & 0.31 & 0.31 & 0.19 \\
\hline $25^{*}$ & $\mathrm{Em}$ & 0.60 & 0.26 & 0.51 & 0.05 \\
\hline 5 & $\mathrm{~F}$ & 0.58 & 0.35 & 0.38 & 0.15 \\
\hline $1^{*}$ & PhS & 0.15 & 0.72 & 0.10 & 0.24 \\
\hline $2^{*}$ & $\mathrm{~F}$ & 0.31 & 0.71 & 0.12 & 0.16 \\
\hline $29^{*}$ & $\mathrm{~F}$ & 0.33 & 0.66 & 0.32 & 0.19 \\
\hline $3^{*}$ & $\mathrm{Em}$ & 0.14 & 0.64 & 0.38 & 0.16 \\
\hline $4^{*}$ & $\mathrm{~F}$ & 0.46 & 0.61 & 0.32 & 0.10 \\
\hline $8^{*}$ & $\mathrm{~F}$ & 0.38 & 0.59 & 0.42 & 0.03 \\
\hline $7^{\star}$ & $\mathrm{PhS}$ & 0.11 & 0.55 & 0.24 & 0.51 \\
\hline $21^{*}$ & $\mathrm{~F}$ & 0.41 & 0.55 & 0.34 & 0.00 \\
\hline $26^{\star}$ & $\mathrm{PhS}$ & 0.23 & 0.51 & 0.21 & 0.24 \\
\hline 22 & $\mathrm{Em}$ & 0.49 & 0.28 & 0.65 & 0.01 \\
\hline 12 & $\mathrm{Em}$ & 0.50 & 0.11 & 0.64 & 0.20 \\
\hline 13 & $\mathrm{Em}$ & 0.21 & 0.28 & 0.64 & 0.25 \\
\hline 20 & $\mathrm{Em}$ & 0.50 & 0.24 & 0.64 & 0.02 \\
\hline 15 & $\mathrm{Em}$ & 0.35 & 0.13 & 0.64 & 0.15 \\
\hline 27 & $\mathrm{Em}$ & 0.37 & 0.28 & 0.62 & 0.19 \\
\hline 6 & $\mathrm{Em}$ & 0.33 & 0.46 & 0.61 & 0.15 \\
\hline 9 & $\mathrm{Em}$ & 0.05 & 0.20 & 0.57 & 0.24 \\
\hline 16 & $\mathrm{PhS}$ & 0.28 & 0.02 & 0.05 & 0.74 \\
\hline 18 & $\mathrm{PhS}$ & 0.29 & 0.34 & 0.31 & 0.63 \\
\hline 23 & PhS & -0.04 & 0.28 & 0.35 & 0.60 \\
\hline 10 & $\mathrm{PhS}$ & 0.20 & 0.49 & 0.06 & 0.56 \\
\hline
\end{tabular}

F-Functioning, PhS - Physical symptoms, Em-Emotions; * this item loaded on the factors different from its original subscale

diagnostic value must be re-evaluated due to potential cross-cultural differences affecting their psychometric properties (i.e., reliability, validity).

Skindex-29 is one of the most recognized, meticulously developed and widely utilized instruments measuring dermatology-specific quality of life. Due to its worldwide common use it has an additional advantage enabling cross-cultural comparisons of quality of life in people with dermatological conditions. The findings presented in this paper - pertaining to the psychometric properties of the Polish version of Skindex-29 - shed more light on the utility of this questionnaire in differ- 
Table 7. Percentage of variance in Skindex-29 explained by the extracted factors

\begin{tabular}{cccc}
\hline Component & $\begin{array}{c}\text { Squared factor } \\
\text { loadings }\end{array}$ & $\begin{array}{c}\text { \% of variance } \\
\text { explained }\end{array}$ & $\begin{array}{c}\text { Cumulative } \\
\text { \% of variance } \\
\text { explained }\end{array}$ \\
\hline 1 & 5.76 & 19.87 & 19.87 \\
\hline 2 & 5.05 & 17.40 & 37.27 \\
\hline 4 & 5.01 & 17.29 & 54.55 \\
\hline
\end{tabular}

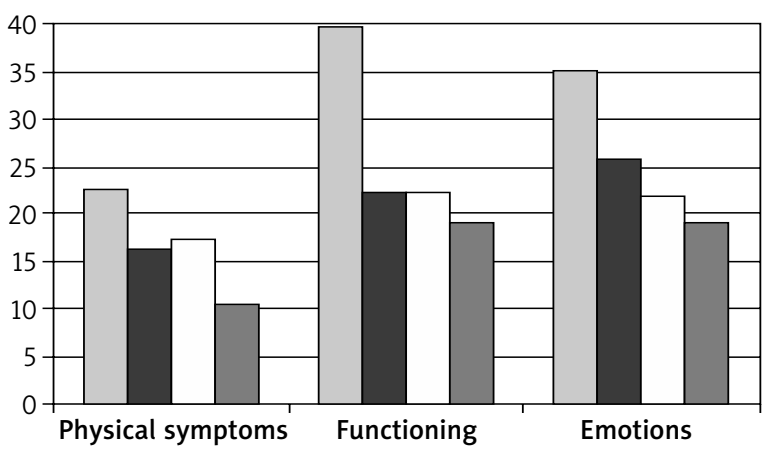

$\square$ Psoriasis $\quad$ Acne vulgaris $\quad$ Skin allergies $\square$ Warts

Figure 2. Skindex-29 scores in subgroups of patients with different skin conditions ent cultural environments and contribute to our knowledge on reliability and validity of this instrument.

Our findings from the Polish sample of patients with a wide range of dermatological conditions varying in etiology, severity, acuity, physical and psychological burden, duration, and prognosis showed that the scores on the global quality of life index (Skindex-29 total score) are distributed across the whole potential scale and are not significantly different from the normal distribution. This indicates that patients vary significantly in their subjective quality of life and Skindex-29 is able to detect this variation.

The findings of this study also showed very high internal consistency of Skindex-29 indexes, providing more support for reliability of measurements made by these in-

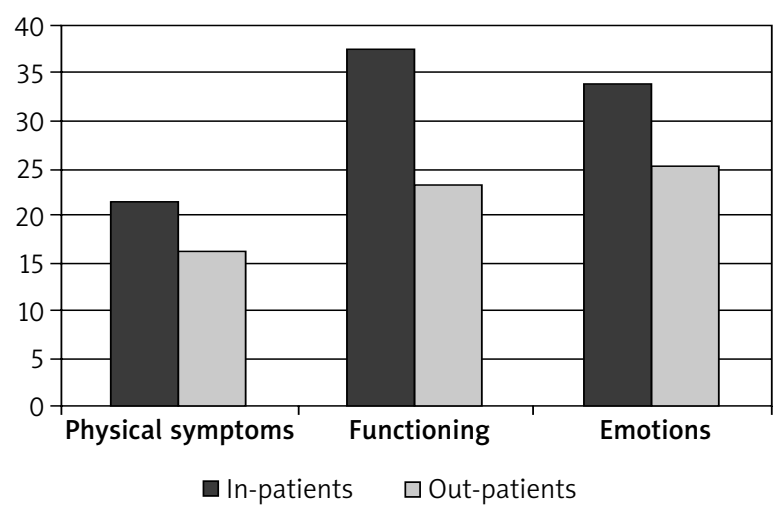

Figure 3. Differences in the Skindex-29 scores between in-patients and out-patients

Table 8. Differences in the Skindex-29 scores between subgroups of patients with different skin conditions

\begin{tabular}{|c|c|c|c|c|c|c|c|c|c|c|}
\hline \multirow[t]{2}{*}{ Skindex-29 indexes } & \multicolumn{2}{|c|}{$\begin{array}{l}\text { Psoriasis } \\
(n=52)\end{array}$} & \multicolumn{2}{|c|}{$\begin{array}{c}\text { Acne vulgaris } \\
(n=58)\end{array}$} & \multicolumn{2}{|c|}{$\begin{array}{l}\text { Warts } \\
(n=19)\end{array}$} & \multicolumn{2}{|c|}{$\begin{array}{l}\text { Skin allergies } \\
\quad(n=19)\end{array}$} & \multicolumn{2}{|c|}{ ANOVA } \\
\hline & Mean & SD & Mean & SD & Mean & SD & Mean & SD & $F$ & $p$ \\
\hline Physical symptoms & 22.42 & 5.12 & 16.09 & 5.19 & 10.53 & 3.10 & 17.21 & 4.69 & 32.00 & $<0.001$ \\
\hline Functioning & 39.65 & 12.10 & 22.10 & 8.43 & 18.89 & 6.67 & 22.05 & 9.95 & 38.53 & $<0.001$ \\
\hline Emotions & 35.12 & 9.74 & 25.67 & 7.44 & 19.00 & 7.30 & 21.79 & 9.85 & 23.32 & $<0.001$ \\
\hline Total score & 97.19 & 25.23 & 63.86 & 17.42 & 48.42 & 15.44 & 61.05 & 21.87 & 37.88 & $<0.001$ \\
\hline
\end{tabular}

SD - standard deviation

Table 9. Differences in the Skindex-29 scores between in-patients and out-patients

\begin{tabular}{|c|c|c|c|c|c|c|}
\hline \multirow[t]{2}{*}{ Skindex-29 indexes } & \multicolumn{2}{|c|}{ In-patients $(n=104)$} & \multicolumn{2}{|c|}{ Out-patients $(n=196)$} & \multicolumn{2}{|c|}{ Student $t$-test } \\
\hline & Mean & SD & Mean & SD & $t$ & $p$ \\
\hline Physical symptoms & 21.47 & 5.79 & 16.01 & 5.41 & 8.04 & $<0.001$ \\
\hline Functioning & 37.26 & 11.88 & 23.22 & 9.97 & 10.73 & $<0.001$ \\
\hline Emotions & 33.92 & 9.60 & 25.08 & 8.90 & 7.89 & $<0.001$ \\
\hline Total score & 92.65 & 24.87 & 64.30 & 21.63 & 10.14 & $<0.001$ \\
\hline
\end{tabular}

SD - standard deviation 
Table 10. Results of stepwise regression analyses for Skindex-29 indexes (dependent variables) with location of lesions introduced as independent variables

\begin{tabular}{|c|c|c|c|c|c|c|c|c|}
\hline \multirow[t]{2}{*}{ Dependent variable } & \multirow{2}{*}{$\begin{array}{l}\text { Variables introduced into } \\
\text { the regression model }\end{array}$} & \multicolumn{3}{|c|}{ Standardized coefficients } & \multicolumn{4}{|c|}{ Parameters of the model } \\
\hline & & $\beta$ & $t$ & $p$ & $R^{2}$ & Corrected $R^{2}$ & $F$ & $p$ \\
\hline \multirow[t]{3}{*}{ Physical symptoms } & Legs & 0.38 & 5.72 & $<0.001$ & 0.20 & 0.19 & 19.77 & $<0.001$ \\
\hline & Anogenital areas & 0.18 & 2.86 & 0.005 & & & & \\
\hline & Face & 0.15 & 2.35 & 0.020 & & & & \\
\hline \multirow[t]{3}{*}{ Functioning } & Legs & 0.32 & 5.18 & $<0.001$ & 0.26 & 0.25 & 28.64 & $<0.001$ \\
\hline & Palms & 0.19 & 3.10 & 0.002 & & & & \\
\hline & Anogenital areas & 0.16 & 2.66 & 0.008 & & & & \\
\hline \multirow[t]{2}{*}{ Emotions } & Legs & 0.28 & 4.46 & $<0.001$ & 0.13 & 0.12 & 17.74 & $<0.001$ \\
\hline & Anogenital areas & 0.16 & 2.50 & 0.013 & & & & \\
\hline \multirow[t]{3}{*}{ Total score } & Legs & 0.31 & 4.97 & $<0.001$ & 0.24 & 0.23 & 24.85 & $<0.001$ \\
\hline & Anogenital areas & 0.17 & 2.82 & 0.005 & & & & \\
\hline & Palms & 0.15 & 2.43 & 0.016 & & & & \\
\hline
\end{tabular}

struments. The reliability coefficient values obtained for the Polish version are very similar to those reported for the original [18]. The psychometric properties of individual Skindex-29 items, as measured by corrected item-total correlations, were also found to be high or very high. Only three items had corrected item-total correlations slightly lower than 0.50, which is still satisfactory.

Factor analysis, which is used for psychometric instruments to test theoretical (factor) validity, yielded a four-factor solution in our sample. This finding is somewhat problematic as the original version was reported to consist of three factors, which in fact were the basis for development of three Skindex-29 subscales [18]. Three out of four factors extracted in the Polish version of Skindex-29 matched almost perfectly the three original subscales: Physical symptoms, Functioning and Emotions, however, the fourth extra factor was combined of items originally belonging to the Physical symptoms and Functioning subscales. A closer analysis of the contents of these items shows that they pertain to: (1) somatic-perceptual sensitivity (sensations of itching, irritation, adverse effects of water on the skin condition and (2) psychological sensitivity - pain or discomfort where the somatic factors affect psychosomatic functioning with a direct impact on the quality of sleep, rest, energy level or fatigue. Items 2, 4, 8 and 29, loading on the additional factor, include symptoms of the depressive type which may affect mental pain and discomfort. Whether this factor could, therefore, correspond to depressive tendencies, still needs clarification and requires further verification. It is possible that the factorial structure of Skindex-29 is not so stable and it can change in various populations. In this context, it is interesting to note that Italian researchers using mixture analysis isolated several lower-order factors within three subscales of the Italian version of Skindex-29 [33]. The extra factor found in our study may thus correspond to or consist of some more easily dis- tinguishable lower-order factors. So far, however, we decided to stick in the Polish version of Skindex-29 to the original proposal of three factors as it will enable comparisons with results of other studies carried out worldwide.

Our study also confirms criterion validity of Skindex-29. The comparisons we made for the Skindex-29 indexes between the subgroups of patients with different types of conditions (psoriasis, acne vulgaris, warts and skin allergies) showed that Skindex-29 yielded the hypothesized inter-group differences. The patients with a more burdensome inflammatory disease (psoriasis) exhibited significantly higher scores on Skindex-29 (indicative of lower quality of life) than those with milder conditions (warts, skin allergies). Similarly, those with more severe conditions, as reflected in the need for hospitalization (in-patients), also scored higher on Skindex-29 than those with milder conditions nor requiring hospital admission (out-patients). Skindex-29 indexes also showed sensitivity to the location of skin lesions, with the location of lesions on legs, anogenital areas, palms and face being the most important for decrement in quality of life. It is of note, however, that the location of lesions was only weakly or moderately predictive of variance in quality of life (corrected $R^{2}$ from 0.12 to 0.25 ). This remains in accordance with other studies showing that subjective quality of life in dermatological patients is only moderately related to disease severity and psychological factors are very potent moderators of this relationship [34, 35].

\section{Conclusions}

The study on the Polish version of Skindex-29 confirms the clinical usefulness of this diagnostic tool. The findings obtained in the Polish population of dermatological patients indicate that this method is reliable and valid, and provides an adequate measure of quality of life in this clinical group. 


\section{Acknowledgments}

A part of this work was done when Dr. Janowski was receiving a scholarship grant from the Polish Ministry of Science and Higher Education.

\section{References}

1. Finlay AY, Coles EC. The effect of severe psoriasis on the quality of life of 369 patients. Br J Dermatol 1995; 132: 236-44.

2. Koo J. Population-based epidemiologic study of psoriasis with emphasis on quality of life assessment. Dermatol Clin 1996; 14: 485-96.

3. Lasek RJ, Chren MM. Acne vulgaris and the quality of life of adult dermatology patients. Arch Dermatol 1998; 134: 454-8.

4. Lundberg L, Johannesson M, Silverdahl M, et al. Health-related quality of life in patients with psoriasis and atopic dermatitis measured with SF-36, DLOI and a subjective measure of disease activity. Acta Derm Venereol 2000; 80: 430-4.

5. Finlay AY, Ryan TJ. Disability and handicap in dermatology. Int J Dermatol 1996; 35: 305-11.

6. Finlay AY. Skin disease disability: measuring its magnitude. Keio J Med 1998; 47: 131-4.

7. Finlay AY, Khan GK, Luscombe DK, Salek MS. Validation of sickness impact profile and psoriasis disability index in psoriasis. Br J Dermatol 1990; 123: 751-6.

8. Salek MS, Finlay AY, Luscombe DK, et al. Cyklosporin greatly improves the quality of life of adults with severe atopic dermatitis. Br J Dermatol 1993; 129: 422-30.

9. Motley RJ, Finlay AY. How much disability is caused by acne? Clin Exp Dermatol 1989; 14: 194-8.

10. Motley RJ, Finlay AY. Practical use of a disability index in the routine management of acne. Clin Exp Dermatol 1992; 17: 1-3.

11. Drake LA, Patrick DL, Fleckman P, et al. The impact of onychomycosis on quality of life: development of an international onychomycosis-specific questionnaire to measure patient quality of life. J Am Acad Dermatol 1999; 41: 189-96.

12. McKenna SP, Cook SA, Whalley D, et al. Development of the PSORIQOL, a psoriasis-specific measure of quality of life designed for use in clinical practice and trials. Br J Dermatol 2003; 149: 323-31

13. Chen SC, Yeung J, Chren MM. Scalpdex. A quality-of-life instrument for scalp dermatitis. Arch Dermatol 2002; 138 803-7.

14. Finlay AY, Khan GK. Dermatology Life Quality Index (DLQI) a simple practical measure for routine clinical use. Clin Exp Dermatol 1994; 19: 210-6.

15. Lewis-Jones MS, Finlay AY. The Children's Dermatology Life Quality Index (CDLQI): initial validation and practical use. $\mathrm{Br}$ J Dermatol 1995; 132: 942-9.

16. Morgan M, McReedy R, Simpson J, Hay RJ. Dermatology quality of life scales - a measure of the impact of skin diseases. Br J Dermatol 1997; 136: 202-6.

17. Grob JJ, Auquier P, Martin S, et al. Development and validation of a quality of life measurement for chronic skin disorders in French: VQ-Dermato. Dermatology 1999; 199: 213-22.

18. Chren MM, Lasek RJ, Flocke SA, Zyzanski SJ. Improved discriminative and evaluative capability of a refined version of Skindex, a quality-of-life instrument for patients with skin diseases. Arch Dermatol 1997; 133: 1433-40.

19. Chren MM, Lasek RJ, Quinn LM, et al. Skindex, a quality-of-life measure for patients with skin diseases: reliability, validity and responsiveness. J Invest Dermatol 1996; 107: 707-13.

20. Chren MM, Lasek RJ, Quinn LM, Covinsky KE. Convergent and discriminative validity of a generic and a disease-specific instrument to measure quality of life in patients with skin diseases. J Inv Dermatol 1997; 108: 103-7.

21. de Korte J, Mombers FM, Sprangers MA, Bos JD. The suitability of quality-of-life questionnaires for psoriasis research: a systematic literature review. Arch Dermatol 2002; 138: 1221-7.

22. Klein R, Moghadam-Kia S, Taylor L, et al. Quality of life in cutaneous lupus erythematosus. J Am Acad Dermatol 2011; 64: 849-58

23. Andreis F, Rizzi A, Mosconi P, et al. Quality of life in colon cancer patients with skin side effects: preliminary results from a monocentric cross sectional study. Health Qual Life Outcomes 2010; 8: 40.

24. Schwegler J, Schwarz J, Eulenburg C, et al. Health-related quality of life and patient-defined benefit of clobetasol $0.05 \%$ in women with chronic lichen sclerosus of the vulva. Dermatology 2011; 223: 152-60.

25. Abeni D, Picardi A, Pasquini P, et al. Further evidence of the validity and reliability of the Skindex-29: an Italian study on 2,242 dermatological outpatients. Dermatology 2002; 204: 43-9.

26. Jones-Caballero M, Penas PF, Garcia-Diez A, et al. The Spanish version of Skindex-29. Int I Dermatol 2000; 39: 907-12.

27. Zghal A, Zeglaoui F, Kallel L, et al. Ouality of life in dermatology: Tunisian version of the Skindex-29. Tunis Med 2003; 81: 34-7.

28. Wolkenstein P, Zeller J, Revuz J, et al. Quality of life impairment in neurofibromatosis type 1 . A cross-sectional study of 128 cases. Arch Dermatol 2001; 137: 1421-5.

29. Chren MM, Lasek RJ, Sahay AP, Sands LP. Measurement properties of Skindex-16: a brief quality-of-life measure for patients with skin diseases. J Cutan Med Surg 2001; 5: 105-10.

30. Higaki Y, Kawamoto K, Kamo T, et al. The Japanese version of Skindex-16: a brief quality-of-life measure for patients with skin diseases. J Dermatol 2002; 29: 693-8.

31. Mtynek A, Magerl M, Hanna M, et al. The German version of the chronic urticaria quality-of-life questionnaire: factor analysis, validation, and initial clinical findings. Allergy 2009; 64: 927-36.

32. Aksu AEK, Urer MS, Sabuncu I, et al. Turkish version of Skindex-29. Int J Dermatol 2007; 46: 350-5.

33. Nijsten T, Sampogna F, Abeni D. Categorization of Skindex-29 scores using mixture analysis. Dermatology 2009; 218: 151-4.

34. Janowski K, Steuden S. Severity of psoriasis and health-related quality of life: the moderating effects of temperament. $\mathrm{Br}$ J Dermatol 2008; 158: 633-5.

35. Kochańska A, Zarzycka B, Świątecka G, et al. Quality of life in patients with an implantable cardioverter-defibrillator - the significance of clinical factors. Arch Med Sci 2008; 4: 409-16. 